\title{
The Cervical Arteries: An Anatomical Study with Application to Avoid the Nerve Root and Spinal Cord Blood Supply
}

\author{
Mehmet ARSLAN 1 , Halil Ibrahim ACAR ${ }^{2}$, Ayhan COMERT ${ }^{2}$, R. Shane TUBBS ${ }^{3}$ \\ ${ }^{1}$ Yuzuncu Yil University, School of Medicine, Department of Neurosurgery, Van, Turkey \\ ${ }^{2}$ Ankara University, School of Medicine, Department of Anatomy, Ankara, Turkey \\ ${ }^{3}$ Seattle Science Foundation, Seattle, WA, USA
}

\section{ABSTRACT}

AIM: Injury to the vascular supply to the cervical spinal cord can lead to the anterior spinal artery syndrome, which is often associated with transforaminal corticosteroid injections to the cervical foramina. The purpose of this cadaveric study was to examine the morphology of the cervical arteries and to emphasize their clinical importance.

MATERIAL and METHODS: Five formalin-fixed human cadavers were used to determine the morphology of the radicular arteries from the vertebral, ascending and deep cervical arteries in the cervical foraminal region.

RESULTS: The mean diameter of the vertebral arteries was $5.50 \mathrm{~mm}$. The radicular arteries arose from the vertebral artery originating from its posterior aspect at each level and the C6 radicular artery was larger in diameter than others. Their diameters ranged from $0.75 \mathrm{~mm}$ to $1.02 \mathrm{~mm}$. The mean diameter of the ascending cervical artery was $1.5 \mathrm{~mm}$ (range 1.21 to $1.80 \mathrm{~mm}$ ). Its arising spinal branches were located at the C3-4 or C4-5 levels. The diameters of radicular branches arising from the ascending cervical artery ranged from $0.80 \mathrm{~mm}$ to $1.40 \mathrm{~mm}$. The mean diameter of the deep cervical artery was $1.71 \mathrm{~mm}$ (range 1.3 to $2.1 \mathrm{~mm}$ ) and was usually slightly larger than the ascending cervical arteries. These deep cervical radicular arteries always entered the C5-6, C6-7 and $\mathrm{C} 7-\mathrm{T} 1$ foramens and those of the radicular branches arising from the deep cervical artery ranged from $0.43 \mathrm{~mm}$ to $1.49 \mathrm{~mm}$ (mean, $1.08 \mathrm{~mm})$.

CONCLUSION: Understanding the vascular supply to the cervical spinal cord is important for preventing serious complications such as spinal cord ischemia.

KEYWORDS: Cervical radicular artery, Ascending cervical artery, Deep cervical artery, Spinal cord injury, Anatomy, Cadaver

\section{INTRODUCTION}

$\longrightarrow$ ervical transforaminal epidural corticosteroid injections are commonly recommended for cervical radiculopathy pain $(2,13,21)$. Additionally, anterolateral surgical decompression of the cervical spine to treat various pathological processes including degenerative disc disease, trauma, deformity, infection and spinal neoplasms is becoming increasingly more common $(7,12,16-19,26)$. Although procedure-related complications are minor, serious complications result if there is infarction of the spinal cord $(6,14,15,24)$.
Injury to the cervical radicular arteries during these approaches is rare. However, injury to the dominant vessels of the vascular supply to the cervical spinal cord can cause spinal cord infarction. Anatomical knowledge of the cervical radicular arteries is therefore important for preventing postoperative neurological complications following procedures on the cervical spine. To our knowledge, there have been few studies published regarding the relationship of radicular arteries to the spinal cord ischemia that can occur following cervical spinal procedures $(2,6,12,13,15,21,24)$. The prevalence of these serious complications is currently unknown.

Corresponding author: Mehmet ARSLAN

E-mail: arslan2002@hotmail.com 
In this study, based on cadaver dissections and observation, we emphasize the surgical importance of the cervical radicular arteries and examine their morphology with the aim of elucidating their clinical importance. We hope our data will help surgeons to minimize the complications following approaches to the cervical spine.

\section{MATERIAL and METHODS}

Five male formalin-fixed human cadavers (ages at death ranging from 48 to 72 years, heights ranging from 164 to 172 $\mathrm{cm}$ ) were used to determine the morphology of the cervical radicular arteries in the cervical foraminal region. Specimens with gross deformities were excluded from the study. The cadavers were placed in the supine position and dissected from C2 to C7, bilaterally. The exposed neurovascular complexes were identified. The internal jugular vein, vagus nerve, and the common, external and internal carotid arteries were exposed after opening the carotid sheath. Beneath the adipose tissue layer encountered during dissection, the prevertebral fascia and the fascia of the longus capitis muscle were explored. The cervical sympathetic trunk and its superior and middle ganglia were exposed. The longus capitis and longus colli muscles were removed to explore the extraforaminal region. On the lateral side of the dissection area were the scalene muscles and the nerve roots passing between them to form the brachial plexus. The $\mathrm{C} 2-\mathrm{C} 7$ vertebrae and disc levels and the anterior tubercles of the C3-C7 transverse processes were demonstrated. To reveal the cervical radicular arteries in the cervical extraforaminal region, intertransverse muscles were removed. The vertebral artery and its venous plexus wrapped within a fibroligamentous sheath were exposed. The level at which the vertebral artery entered a transverse foramen was determined. Its course throughout its second segment (V2) and its relationships with nerve roots were identified. The ascending cervical artery, which originates from the thyrocervical trunk, was exposed. We took great care to protect the neural and vascular structures. The subclavian artery and its branches and the roots of the brachial plexus were isolated by dissection. Spinal branches originating from the deep cervical, ascending cervical and vertebral arteries were noted, and in particular the arterial origin, diameter and location were recorded. The arterial diameters were measured at the external foraminal opening.

A surgical microscope (Zeiss OPMI 9-FC) was used to facilitate the dissections. All measurements were made bilaterally using a digital caliper accurate to $0.01 \mathrm{~mm}$. The average, standard deviation (SD) and minimum and maximum values were determined. Wilcoxon Signed Ranks tests were used to assess differences between sides. Statistical significance was set at $p<0.05$. The following measurements were obtained:

1. The diameter of the vertebral artery (V2) at the C3, C4, C5, and $\mathrm{C} 6$ levels.

2. The diameter of the radicular artery at the $\mathrm{C} 3, \mathrm{C} 4, \mathrm{C} 5$, and C6 levels.

3. The diameter of the ascending cervical artery at its origin.

4. The diameter of the deep cervical artery at its origin.

\section{- RESULTS}

The vertebral arteries arose from the subclavian artery and entered the transverse foramen at the C6 level on both sides of the cadavers, accompanied by the anterior and posterior vertebral veins, which formed mesh-like structures around them. The vertebral artery, the venous plexus and the nerve roots were encased in fibroligamentous tissue at the level of the intertransverse space (Figure 1). This tissue was attached to the lateral aspect of the spine. Between two transverse processes, the vertebral artery crossed anteriorly to the cervical nerve root and adhered to it. It was free and was enclosed with the venous plexus. Along its course, the vertebral artery gave origin to several branches, the most important being the radicular arteries (Figure 2). The diameters of the radicular branches of the vertebral artery ranged from $0.75 \mathrm{~mm}$ to $1.02 \mathrm{~mm}$. These arteries most often arose from the posterior surface of the vertebral artery at the C6 level. Additionally, the medial and anterior branches from the vertebral artery were directed to anterior longitudinal ligamentous structures, the intervertebral disc and the vertebral body (Figure 3). The diameters of these branches were usually below $1 \mathrm{~mm}$. The mean diameters of the V2 segment of the vertebral artery from the C3 to the C6 level were $5.25 \mathrm{~mm}, 5.59 \mathrm{~mm}, 5.65 \mathrm{~mm}$, and $5.53 \mathrm{~mm}$. The average diameter of the vertebral arteries was $5.50 \mathrm{~mm}$.

The ascending cervical artery typically arose from the thyrocervical trunk (Figure 4). Its mean diameter was $1.5 \mathrm{~mm}$ at the origin, ranging from 1.21 to $1.80 \mathrm{~mm}$. It gave a spinal

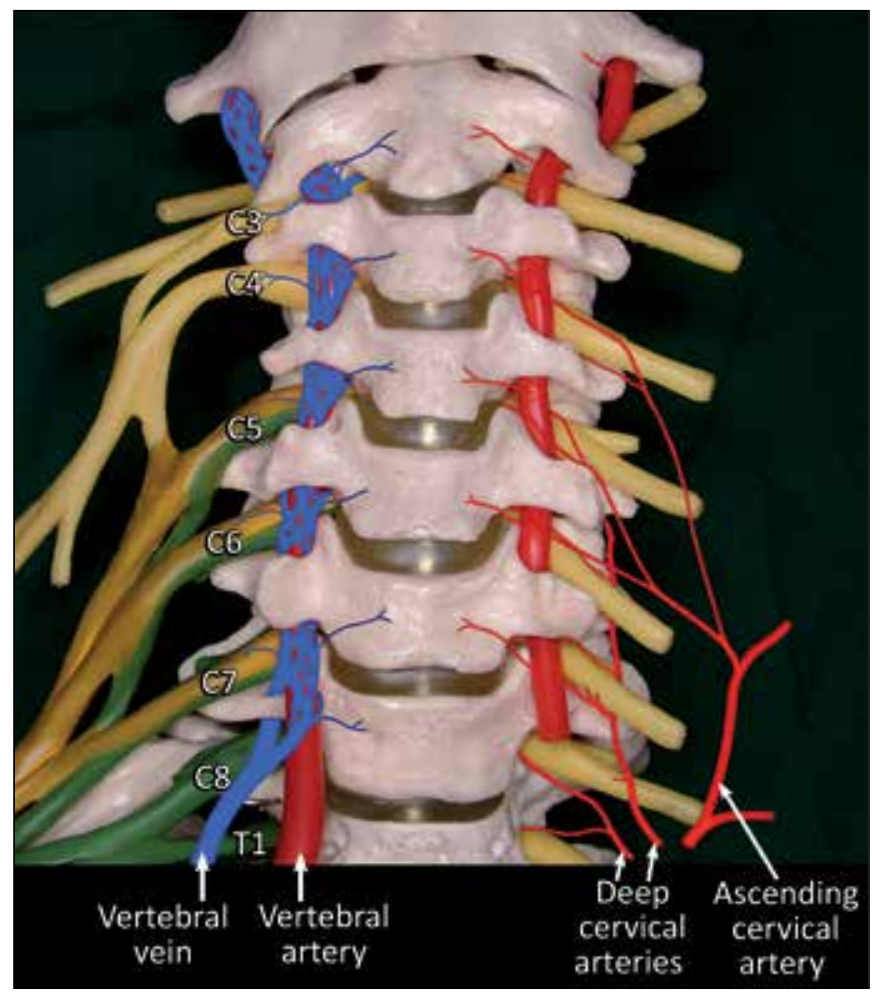

Figure 1: Drawing shows the V2 segment of the vertebral artery, the vertebral venous plexus, the ascending cervical artery, the deep cervical artery and their radicular branches. 
branch to the C3-4 and C4-5 foramen, rarely C2-3 (Figures $4,5,7)$. Its radicular branches coursed anteriorly, anteroinferiorly or anterosuperiorly to the $\mathrm{C} 4$ and $\mathrm{C} 5$ nerve roots. The radicular branches of the ascending cervical artery did not pass into the dorsal aspect of the foramen. They penetrated anterosuperior and anteroinferior to the $\mathrm{C} 4$, and $\mathrm{C} 5$ nerve root sleeves at the C3-4 and C4-5 foramen. The diameters of the radicular arteries originated from the ascending cervical artery ranged from 0.80 $\mathrm{mm}$ to $1.40 \mathrm{~mm}$. In the cadaver, the $\mathrm{C} 4$ spinal radicular artery had a greater diameter than the others (Figure 5).

The deep cervical artery generally arose as one or more vessels from the costocervical trunk (Figure 6). In one cadaver, one of two deep cervical arteries originated from the costocervical trunk and the other from the subclavian artery. However, in many cases the artery migrated more posteriorly, between the facet joints into its more classic location toward the posterior spinal muscles. In this study, the mean diameter of the deep cervical artery was $1.71 \mathrm{~mm}$, ranging from 1.3 to $2.1 \mathrm{~mm}$ and usually slightly larger than the ascending cervical arteries. In all five cadavers, the deep cervical artery formed large radicular branches that entered the posterior aspect of the foramen (Figures 6,7). In each case, these deep cervical spinal branches always entered at C5-6, C6-7 and C7-T1 and pierced the dural sleeve of the corresponding nerve within the neural foramen. During its course, the deep cervical artery gave rise to radicular branches to the foramina posteriorly. The C6, $\mathrm{C} 7$ and $\mathrm{C} 8$ radicular arteries penetrated the dural sleeve within the posterior inferior portion of the foramen, directly inferior to the exiting spinal nerve. The mean diameter of these radicular branches originated from the deep cervical artery was 1.08 $\mathrm{mm}$ (range 0.43 to $1.49 \mathrm{~mm}$ ). The diameters were smaller at upper than at lower levels. The radicular branches from the vertebral artery lay over the most anteromedial part of the foramen, whereas those arising from other sources traversed the entire extent of the foramen. There were no significant

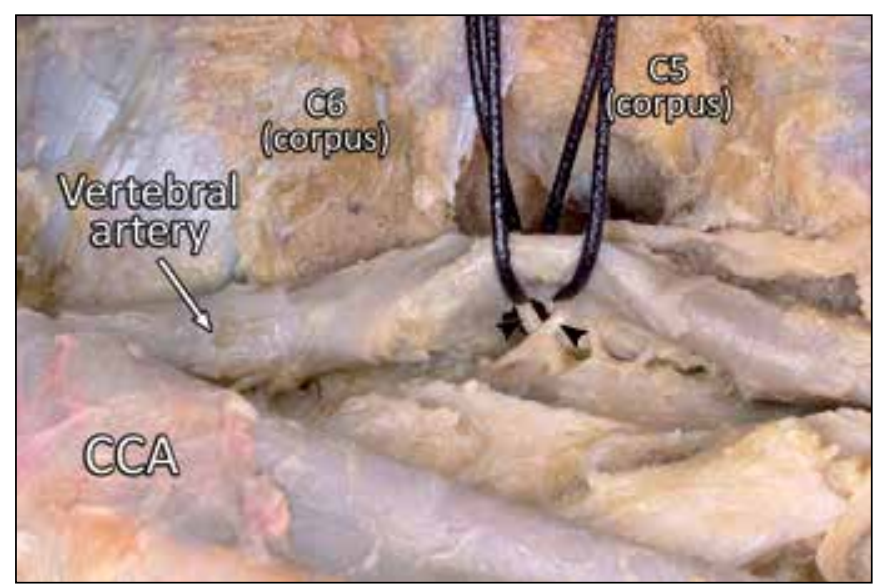

Figure 2: Lateral view of the vertebral artery in the extraforaminal region. The C6 transverse process was removed to reveal it. At the C5-6 foraminal region, the radicular branches arose from the posterior aspect of the vertebral artery. Two radicular arteries entered the foramen on the anterior aspect of the C6 spinal nerve root. Black arrowheads indicate radicular arteries, CCA: Common carotid artery.

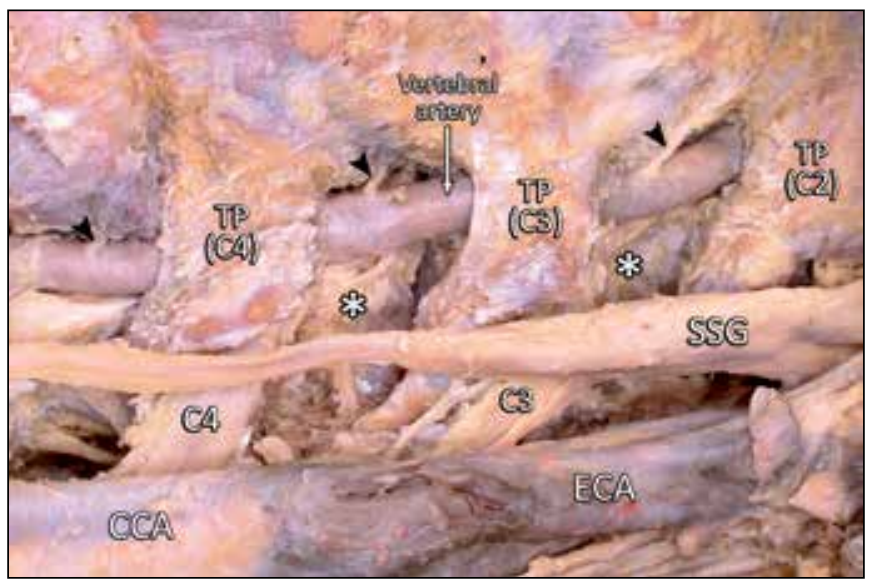

Figure 3: On the left side of the cervical spine, an anterolateral view of the extraforaminal region. Black arrowheads indicate arteries arising from the anterior and medial aspects of the vertebral artery. They were directed to the intervertebral disc and the vertebral body. White star: facet joint, TP: Transverse process, SSG: Superior cervical ganglion of the sympathetic trunk, CCA: Common carotid artery, ECA: External carotid artery.

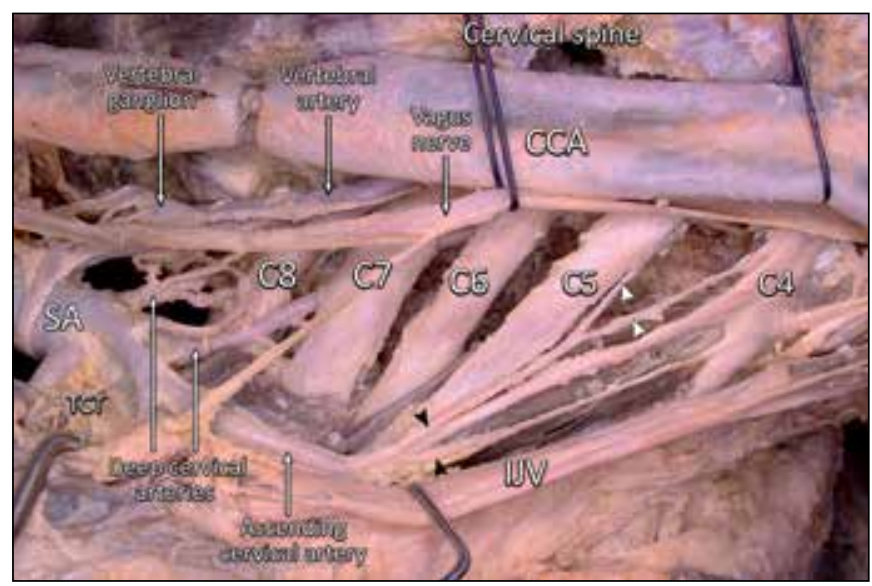

Figure 4: Left side of the cervical spine; anterolateral view of the extraforaminal region. The common carotid artery and the vagus nerve were retracted medially and the internal jugular vein was retracted laterally to demonstrate the cervical spinal roots and cervical arteries. The ascending cervical artery arose from the thyrocervical trunk and supplied a spinal branch at the C3-4 or C4-5 foramen. The radicular branches of the ascending cervical artery coursed anterior, anteroinferior or anterosuperior to the $\mathrm{C} 4$ and C5 nerve roots. One deep cervical artery originated from the costocervical trunk, another from the subclavian artery. The artery migrated toward the posterior aspect of the nerve roots. They gave rise to the foraminal branches in the posterior and posteroinferior aspects of the $\mathrm{C} 6, \mathrm{C} 7$, and $\mathrm{C} 8$ nerve roots. From one deep cervical trunk, several foraminal branches originated. The deep cervical artery formed large radicular branches that entered the posterior aspect of the foramen directly posterior to the exiting ventral ramus. Black arrowheads indicate branches of the ascending cervical artery and white arrowheads show radicular branches. C4, C5, C6 and C7: Spinal nerve roots, CCA: Common carotid artery, IJV: Internal jugular vein, SA: Subclavian artery, TCT: Thyrocervical trunk. 


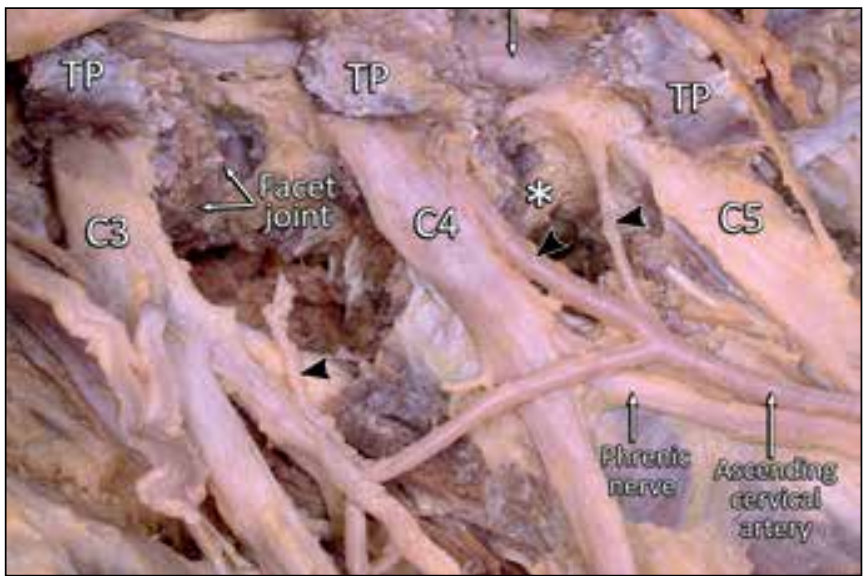

Figure 5: Anterolateral view of the extraforaminal region at the C3, C4 and C5 levels. The radicular branches of the ascending cervical artery coursed anterior, anteroinferior or anterosuperior to the $\mathrm{C} 4$ and $\mathrm{C} 5$ nerve roots. The radicular artery coursed on the anteroinferior aspect of the C4 root and the anterosuperior aspect of the $\mathrm{C} 5$ root. Here it gave a branch to the C3 root. SC: Sympathetic trunk, TP: transverse process, C3, C4, C5: Nerve roots.

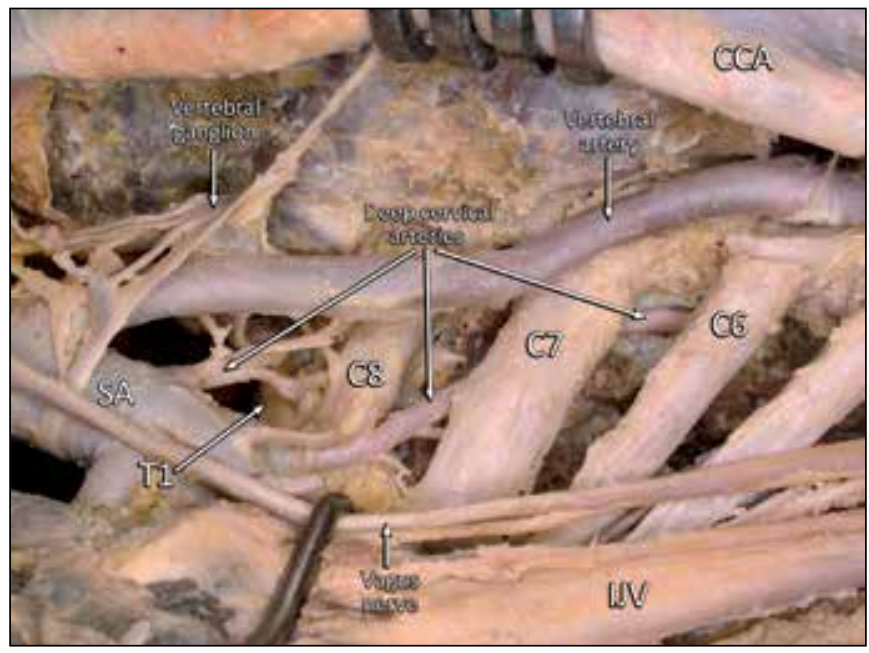

Figure 6: Anterolateral view of the extraforaminal region, lower levels. The common carotid artery was retracted medially, and the internal jugular vein and vagus nerve were retracted laterally, to reveal the cervical spinal roots and cervical arteries. One deep cervical artery originated from the costocervical trunk, another from the subclavian artery. The latter migrated toward the posterior aspect of the nerve roots. These arteries gave rise to the foraminal branches to the posterior and posteroinferior aspects of the C6, C7, and C8 nerve roots. Several foraminal branches arose from one deep cervical trunk. The deep cervical artery formed radicular branches that entered the posterior aspect of the foramen directly posterior to the exiting ventral ramus. C6, C7, C8 and T1: Spinal nerve roots, CCA: Common carotid artery, IJV: Internal jugular vein, SA: Subclavian artery.

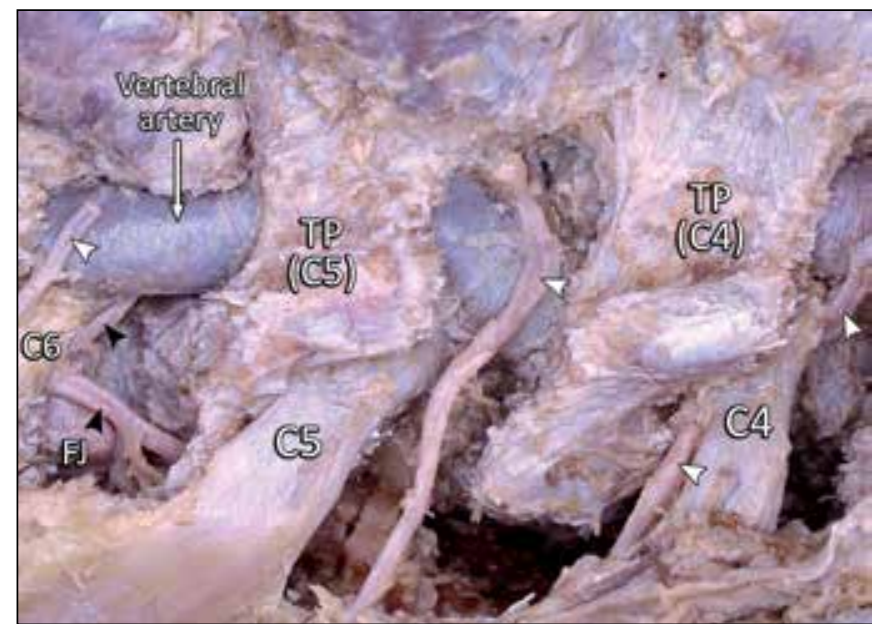

Figure 7: Anterolateral view of the C4-5 and C5-6 extraforaminal region. At the C5-6 foraminal level, behind the C6 nerve root, the deep cervical artery divided into two branches (black arrowheads): the spinal branch entered the foramen posteriorly, and the muscular branch passed toward the posterior spinal muscles on the lateral aspect of the facet joint (FJ). At the C4-5 foraminal level, the ascending cervical artery gave branches to the foramen anteriorly and to the spinal wall. Here, the C4 radicular artery coursed on the anteroinferior aspect of the C4 nerve root.

differences in the results between right and left sides $(p<0.05)$. The results are presented in Table I.

\section{DISCUSSION}

The anterolateral approach is used for transforaminal cervical discectomies and oblique cervical corpectomy (7,12,16-19,26). Additionally, transforaminal injections of corticosteroids have been popularized for treating cervical radiculopathy $(2,13,21)$. Injury to the vascular supply to the cervical spinal cord can lead to anterior spinal artery syndrome, which is most commonly associated with a transforaminal corticosteroid injection to the cervical foramina $(2,6,13-15,21,24)$. However, the risk of vascular compromise to the spinal cord during unilateral anterior spinal surgery remains controversial. The incidence of spinal cord infarction is very low for transforaminal corticosteroid injection (1-3\%) (15), but it is very serious complication resulting in irreversible and permanent neurological injury.

The radicular arteries that join the anterior spinal artery perfused the spinal cord are clinically important $(4,5,10,13,20)$. Various authors have reported lasting paraplegia caused by injury to the dominant spinal arteries after administration of a nerve root block and steroid transforaminally (13,19-21).

There is no agreement regarding the origin of the dominant spinal artery in the cervical region. Adamkiewicz (1), Bolton (3), Chakravorty (6), Dommisse $(8,9)$ stated that the spinal branches of the vertebral artery are very important for filling the anterior spinal trunk. Chakravorty (6) observed 31 human cervical spinal cords and found that many radicular vessels from the vertebral artery contributed to the anterior spinal 
artery. Gillilan (11), Suh and Alexander (22) noted that the upper 6 cervical segments of the spinal cord were supplied by the vertebral artery, and the lower region of the cord received blood from the ascending cervical or deep cervical arteries. Russo et al.(19) stated that all segments of the cervical spine can have radicular arteries arising from the ascending cervical and vertebral arteries. Smuck and Leung (21) reported that the radicular arteries at $\mathrm{C} 5, \mathrm{C} 6, \mathrm{C} 7$ and $\mathrm{T} 1$ arise from the deep cervical and the superior intercostal arteries.

Chakravorty (6) reported that the dominant spinal artery can arise at any level from $\mathrm{C} 3$ to $\mathrm{C} 8$, but $\mathrm{C} 4, \mathrm{C} 5$ and $\mathrm{C} 6$ was most common. However, Turnbull et al.(25) found that vessels with a large diameter are almost equally common at all levels from C4 to C8. Zulch (28), and Woollam and Millen (27), reported a predominance of anterior radicular arteries at the sixth and seventh segments in postmortem examinations.

In the current study, the radicular arteries were found at each level. The branches from the ascending cervical artery tended to enter the foramen just anteroinferior and anterosuperior to the exiting spinal nerve root and course along the anteroinferior and anterosuperior aspect of the spinal nerve until they penetrated the dura to join the spinal artery. The C6, C7 and C8 radicular arteries from the deep cervical artery penetrated the dural sleeve within the postero-inferior portion of the foramen, directly inferior and posterior to the exiting spinal nerve. The radicular branches the ascending and deep cervical artery coursed the entire length of the intervertebral foramen, whereas branches from the vertebral artery were first encountered medially within the foramen.

The number, diameter and distribution of the cervical radicular arteries are important in spinal cord injury. The present study revealed that there are one or two radicular arteries at each level in each cadaver. The larger-diameter radicular arteries can contribute to supplying the spinal cord. In the current study, the diameter of right C4 radicular artery was larger than others (Figure 5). The $\mathrm{C} 7$ and $\mathrm{C} 8$ radicular arteries were slightly larger in diameter than those at the upper end, and their course was posterior to the foramen. Therefore, we consider that the $\mathrm{C} 4$ radicular artery may be dominant radicular artery. However, the needle seems most likely to encounter a large radicular artery at lower levels during cervical transforaminal corticosteroid injection and may cause the spinal cord ischemia. Chakravorty (6) observed that after receiving a radicular artery, the diameter of the anterior spinal artery often increased slightly. This would support the hypothesis that the radicular arteries contribute to the anterior spinal artery.

Table I: The Parameters (mm) of the Cervical Arteries

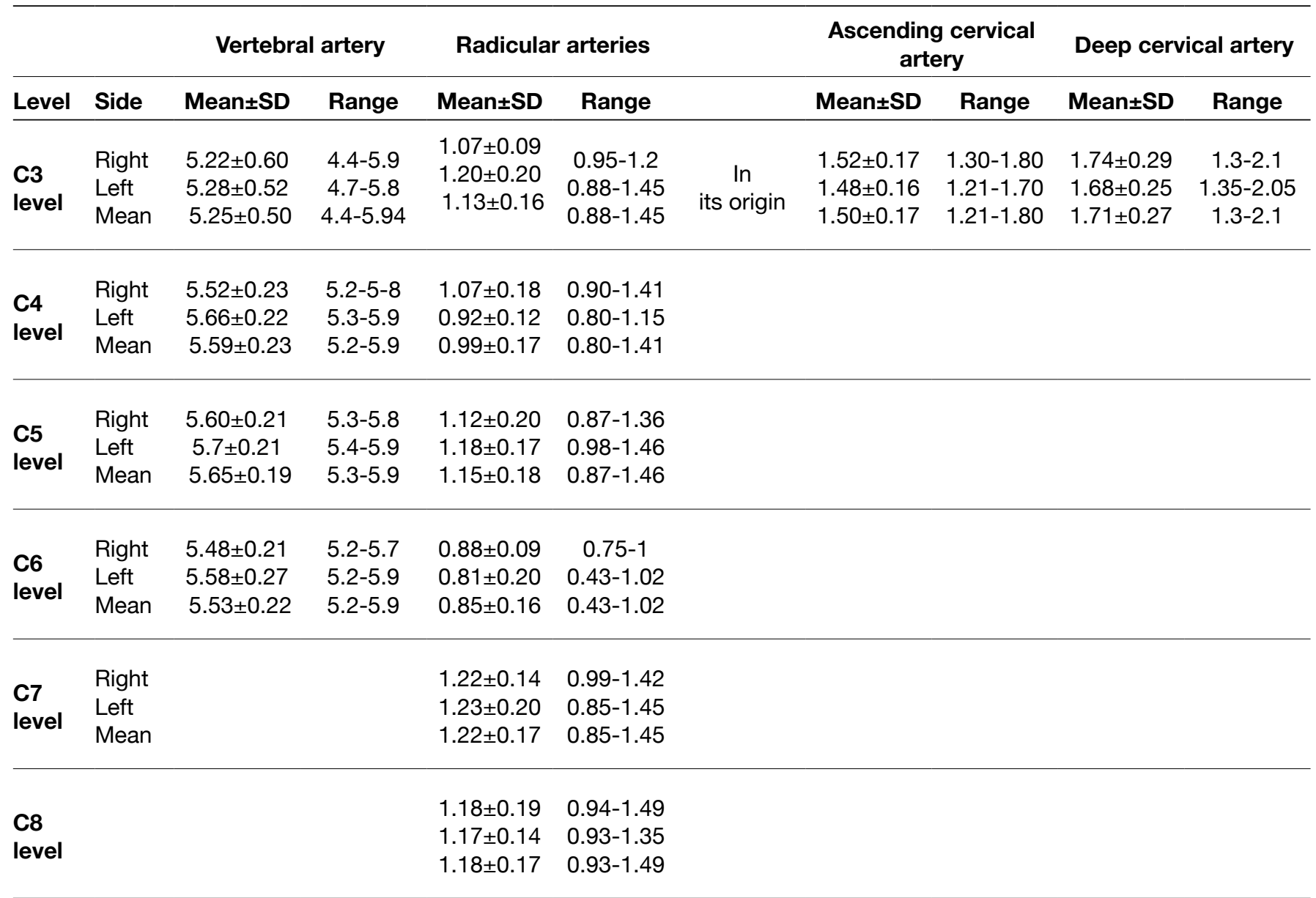


Cervical tranforaminal injections have sometimes resulted in serious complications. Spinal cord infarction has been attributed to transforaminal injections of corticosteroids (2), but the exact cause of this catastrophic complication is not known. The radicular arteries could be responsible for spinal cord infarctions associated with such injections, compromising a critical supply to the anterior spinal artery (2). Accidental cannulation of one of these vessels would always result in neurological injury. Vasospasm is a possible cause of neurological injury and intraarterial injections of particulate corticosteroids seem to be the principal mechanism $(2,15,21)$. With current transforaminal techniques, the radicular artery is avoided by keeping the needle coaxial to, and over the posterior aspect of the foramen (13). When this approach is used, the radicular arteries lie anterior to the course of the needle $(2,13)$. Most authors believe the posterior aspect of the foramen should be preferred for needle placement in order to avoid injury to the arteries. However, cadaveric studies of Hoeft et al.(13) and Huntoon (15) have been reported that the radicular arteries were also located at the posterior aspect of the foramen at lower levels, especially. In the present study, all of the C6, C7 and C8 radicular arteries coursed on the posterior aspect of the nerve root in the foramen. Therefore, the posterior aspect of the foramen is also not safe. Several methods have been used to avoid unintended intravascular injection. When inadvertent radicular artery injections have been detected, fluoroscopy and digital subtraction have been used and injury prevented (21).

Mobilization of the V2 segment of the vertebral artery during the cervical foraminal approach can cause accidental avulsion of the radicular branches from the vertebral artery and any resultant bleeding can be difficult to control. Also, on the basis of our findings, dissection during foraminal approaches should not be extended posterior aspect to the vertebral artery or close to the nerve root. If the radicular vessels are properly protected, complications can be prevented. According to this study, the cervical radicular artery, vertebral artery, ascending cervical artery and deep cervical arteries should if possible be preserved, especially during foraminal procedures and neck dissections.

In the light of above information, the dominant cervical spinal artery can be very variable. Therefore, preoperative imaging is desirable. However, somatosensory evoked potentials can also predict neurological outcomes reliably when the foraminal or extraforaminal region is approached. Care must be taken not to injure or cauterize blood vessels in the intervertebral foramen because of the close proximity of the radicular arteries to the nerve root. This information should be kept in mind to preclude injury to the radicular artery. Coagulation of the dominant spinal branch within the foramen can result in spinal cord injury. According to Houten and Errico (14), injury to the dominant spinal artery in the neural foramen can occur distal to anastomotic artery and can lead to spinal cord infarction. In the present study we encountered collateral links between vessels in the foraminal and extraforaminal area. We consider these anastomoses to be important for supplying the spinal cord. Also, if there is only one major radicular artery, it can be compressed in degenerative diseases involving the foraminal region. This increases the risk of injury and makes ischaemic degeneration of the cord inevitable.

Based on these observations, the anatomy and location of the radicular arteries that supply the anterior and posterior spinal arteries are very variable in the extraforaminal and foraminal region. This variability increases the risk of potential injury. Thus, surgeons cannot rely entirely on standard anatomy for safety. The cadaver study by Huntoon (15) indicated that the risk of neurological injury from transforaminal corticosteroid injections was $3 \%$. All studies have led to much the same conclusion, that the radicular arteries are essential for maintaining the blood supply to the spinal cord $(6,15,23)$. Branches from the vertebral artery, the ascending cervical artery and the deep cervical artery are important in contributing blood to the main anterior spinal artery. One or several major radicular arteries in the cervical cord could be capable of bringing sufficient blood into the anterior spinal artery. Based on our dissection, the dominant anterior radicular artery can originate from various levels: from the vertebral artery at the C5-6 foramen (C6 radicular artery) (Figure 2); from the ascending cervical artery at the C3-C4 foramen (C4 radicular artery) (Figure 5); and from the deep cervical artery at the C7-C8 (Figures 4,6) foramina. Therefore, based on the current study, we believe that the radicular branches should be preserved to prevent spinal cord injury

The origins and locations of these critical arteries can vary anatomically. It was therefore not difficult to isolate the area of the cervical cord supplied by them. The variations must be kept in mind by spinal surgeons. By preserving the radicular arteries, neurological complications following foraminal surgery can be minimized, and it is possible to identify these vessels via preoperative angiograms.

This study was limited to the dissection of five cadaveric specimens and all of the dissected cadavers were male. The use of formalin-fixed cadavers can alter anatomical relationships because the tension within the tissues is decreased. The average linear shrinkage was $4.5 \%$, corresponding to a volume correction factor of 1.15 in the present study.

\section{- CONCLUSION}

Although the vascular supply to the spinal cord can show many variations, a detailed understanding of it is essential. Anatomical knowledge of this region enables a safe surgical approach to be taken, so associated injuries are minimized.

\section{ACKNOWLEDGMENTS}

The authors wish to thank the donors and the family of the donors used for this research.

\section{- REFERENCES}

1. Adamkiewicz A: Die blutgefasse des menschlichen ruckenmarkes oberfiache. Sitz d Wiss in Wien Math Natur Klass 85: 101-135, 1882 (In German) 
2. Baker R, Dreyfuss P, Mercer S, Bogduk N: Cervical transforaminal injection of corticosteroids into a radicular artery: A possible mechanism for spinal cord injury. Pain 103(1-2): 211-215, 2003

3. Bolton B: The blood supply of the human spinal cord. J Neurol Psych 2: 137-148, 1939

4. Bosmia AN, Hogan E, Loukas M, Tubbs RS, Cohen-Gadol AA: Blood supply to the human spinal cord: Part I. Anatomy and hemodynamics. Clin Anat 28(1): 52-64, 2015

5. Bosmia AN, Tubbs RS, Hogan E, Bohnstedt BN, Denardo AJ, Loukas M, Cohen-Gadol AA: Blood supply to the human spinal cord: Part II. Imaging and pathology. Clin Anat 28(1): 65-74, 2015

6. Chakravorty BG: Arterial supply of the cervical spinal cord (with special reference to the radicular arteries). Anat Rec 170: 311-330, 1971

7. Civelek E, Kiris T, Hepgul K, Canbolat A, Ersoy G, Cansever T: Anterolateral approach to the cervical spine: Major anatomical structures and landmarks. Technical note. J Neurosurg Spine 7(6): 669-678, 2007

8. Dommisse GF: The arteries, arterioles, and capillaries of the spinal cord: Surgical guidelines in the prevention of postoperative paraplegia. Ann R Coll Surg Engl 62:369-376, 1980

9. Dommisse GF: The blood supply of the spinal cord: A critical vascular zone in spinal surgery. J Bone Joint Surg Br 56:225235, 1974

10. Gao L, Wang L, Su B, Wang P, Ye J, Shen H: The vascular supply to the spinal cord and its relationship to anterior spine surgical approaches. Spine J 13(8): 966-973, 2013

11. Gillilan LA: The arterial blood supply of the human spinal cord. J Comp Neur 110:75-103, 1958

12. Guvencer M, Men S, Naderi S, Kiray A, Tetik S: The V2 segment of the vertebral artery in anterior and anterolateral cervical spinal surgery: A cadaver angiographic study. Clin Neurol Neurosurg 108(5):440-445, 2006

13. Hoeft MA, Rathmell JP, Monsey RD, Fonda BJ: Cervical transforaminal injection and the radicular artery: Variation in anatomical location within the cervical intervertebral foramina. Reg Anesth Pain Med 31(3):270-274, 2006

14. Houten JK, Errico TJ: Paraplegia after lumbosacral nerve root block: Report of three cases. Spine J 2(1):70-75, 2002
15. Huntoon MA: Anatomy of the cervical intervertebral foramina: Vulnerable arteries and ischemic neurologic injuries after transforaminal epidural injections. Pain 117(1-2):104-111, 2005

16. Lu J, Ebraheim NA, Georgiadis GM, Yang H, Yeasting RA: Anatomic considerations of the vertebral artery: Implications for anterior decompression of the cervical spine. J Spinal Disorders 11(3):233-236, 1998

17. Lu J, Ebraheim NA: The vertebral artery: Surgical anatomy. Orthopedics 22(11):1081-1085, 1999

18. Paolini S, Lanzino G: Anatomical relationships between the V2 segment of the vertebral artery and the cervical nerve roots. J Neurosurg Spine 5(5):440-442, 2006

19. Russo VM, Graziano F, Peris-Celda M, Russo A, Ulm AJ: The $\mathrm{V}(2)$ segment of the vertebral artery: Anatomical considerations and surgical implications. J Neurosurg Spine 15(6):610-619, 2011

20. Schneider GS: Anterior spinal cord syndrome after initiation of treatment with atenolol. J Emerg Med 38(5): e49-52, 2010

21. Smuck M, Leung D: Inadvertent injection of a cervical radicular artery using an atraumatic pencil-point needle. Spine (Phila Pa 1976) 36(3):E220-223, 2011

22. Suh T, Alexander L: Vascular system of the human spinal cord. Arch Neurol Psych 31:659-677, 1939

23. Sunderland S: Meningeal-neural relations in the intervertebral foramen. J Neurosurg 40:756-763, 1974

24. Tator $\mathrm{CH}$, Koyanagi I: Vascular mechanisms in the pathophysiology of human spinal cord injury. J Neurosurg 86(3):483-492, 1997

25. Turnbull IM, Brieg A, Hassler O: Blood supply of cervical spinal cord in man. A microangiographic study. J Neurosurg 24:951965, 1966

26. Verbiest HA: Lateral approach to the cervical spine: Technique and indications. J Neurosurg 28(3):191-203, 1968

27. Woollam DHM, Millen JW: Discussions on vascular disease of the spinal cord. Proc Roy Soc Med 51:540-543, 1958

28. Zulch KJ: Mangeldurchblutung an der gefassegebiete als ursache bisher ungeklarter ruchenmarksschadigungen. Dtscn Z Nervenheilk 172:81-101, 1954 